\title{
The physiological expression of inducible nitric oxide synthase (iNOS) in the human colon
}

\author{
P J Roberts, G P Riley, K Morgan, R Miller, J O Hunter, S J Middleton
}

\begin{abstract}
Background-Inducible nitric oxide synthase (iNOS) is expressed in the colonic epithelium in both inflammatory bowel disease and colorectal cancer. Nitric oxide (NO), the product of this enzyme, has been implicated in the pathogenesis of both conditions. However, there are conflicting data on whether iNOS is expressed in the normal, uninflamed human colon. Aims-To evaluate the expression of iNOS in histologically normal, non-inflamed human colonic mucosa.

Patients/Methods-Reverse transcription polymerase chain reaction (RT-PCR), immunoblotting, and immunohistochemistry were used to investigate the expression of iNOS in 17 histologically normal specimens obtained at colectomy performed for colorectal neoplasia. In addition, 16 endoscopic mucosal biopsies, taken from normal individuals, were also evaluated. Eleven surgical specimens and 16 endoscopic biopsies from patients with refractory ulcerative colitis were used as inflammatory controls.
\end{abstract}

Results-All types of specimens expressed iNOS mRNA. Immunoblotting revealed a protein of approximately $130 \mathrm{kDa}$ consistent with iNOS in mucosal extracts of $77 \%$ of normal individuals, and $85 \%$ of diseased controls. Immunolabelling localised this protein to the surface epithelium in most of the normal specimens and also to the crypt epithelium and inflammatory cells in the diseased controls.

Unit E7, Box 201A Department of Gastroenterology, Addenbrookes

Hospital, CB2 2 QQ

Cambridge, UK

P J Roberts

R Miller

J O Hunter

S J Middleton

Rheumatology

Research Unit, Addenbrookes Hospital

G P Riley

Department of

Biochemistry,

University of

Cambridge,

Cambridge, UK

K Morgan

Correspondence to: Dr Middleton

stephen.middleton@msexc. addenbrookes.anglox.nhs.uk

Accepted for publication 5 June 2000 defence against pathogenic microorganisms.

(F Clin Pathol 2001;54:293-297)

Keywords: inducible nitric oxide synthase; ulcerative colitis; nitric oxide; colorectal carcinoma

Nitric oxide (NO) is produced by the oxidation of the guanidino nitrogen atom of L-arginine by the nitric oxide synthases (NOS). ${ }^{1}$ These are broadly categorised into calcium dependent constitutive isoforms (endothelial NOS (eNOS) and neuronal NOS (nNOS)) and the calcium independent inducible isoform (iNOS), which is produced by a variety of mammalian cells as a result of cytokine and/or bacterial endotoxin stimulation. ${ }^{2-4}$ iNOS expression in the human colon is believed to be dependent upon inflammatory conditions such as those occurring in ulcerative colitis. ${ }^{5-14}$ However, recent evidence suggests that iNOS is constitutively expressed in some tissues, such as the epithelium of human lung, ${ }^{15}$ and in the mouse ileal mucosa, ${ }^{16}$ with the plausible hypothesis that luminal antigens provide the stimulus for iNOS expression at these sites.

The colonic epithelium is continuously exposed to a variety of luminal factors (which might be modified by diet-for example, bacterial endotoxin), with the potential for iNOS induction. Rat colonic epithelial cells in culture express iNOS in the presence of bacterial endotoxin. ${ }^{17}$ Whether this isoform is expressed in a constitutive manner in the human colon is still a matter of debate, with conflicting data in the literature. In one study, iNOS was found in all normal mucosal specimens evaluated, whereas it was absent from cancer specimens. ${ }^{18}$ Another study, comparing the expression of this isoform in normal colon, adenomas, and carcinomas, gave contrasting results in that little or no expression was found in normal tissue. ${ }^{19}$ Therefore, we evaluated iNOS expression in the normal human colon as detailed below.

\section{Patients and specimens}

SURGICAL SPECIMENS

Histologically normal tissue was obtained during colectomy from patients with colorectal neoplasia from a site distant from the lesion. Full thickness biopsies were taken in four of these patients before colectomy, to control for any possible effect of surgical manipulation on iNOS expression. Surgical specimens from patients with refractory ulcerative colitis were used as inflammatory controls, with all patients receiving the same bowel preparation before surgery (table 1). Tissues were frozen immediately and stored at $-70^{\circ} \mathrm{C}$ until analysis.

\section{ENDOSCOPIC BIOPSIES}

Histologically normal mucosal biopsies obtained at rigid sigmoidoscopy $(\mathrm{n}=8)$ and colonoscopy $(n=8)$ were obtained from patients attending the outpatient department who were later shown to have normal colons on either barium enema or full colonoscopy. It was felt necessary to analyse endoscopic biopsies from these normal colons because they were not influenced by any local carcinogenic factors or surgical stress and manipulation, two possible stimulants that might have influenced iNOS expression in the surgical specimens. 
Table 1 Surgical specimens

\begin{tabular}{|c|c|c|}
\hline & Histologically normal specimens & Specimens from patients with $U C$ \\
\hline Mean age (years) & 55 (range, 40-78) & 40 (range, 33-60) \\
\hline Sex & 9 men, 8 women & 6 men, 5 women \\
\hline Medication & Nil & $\begin{array}{l}\text { Azathioprine }(\text { dose }, 2.5 \mathrm{mg} / \mathrm{kg} ; \mathrm{n}=6) \\
5 \text {-ASA (dose, } 2.4 \mathrm{~g} / \text { day; } \mathrm{n}=11) \\
\text { Methylpredisolone (mean dose, } 500 \mathrm{mg} / \text { day; } \mathrm{n}=11 \text { ) }\end{array}$ \\
\hline Site of disease & $\begin{array}{l}\text { Left sided neoplasm }(n=9) \\
\text { Right sided neoplasm }(n=8)\end{array}$ & Pancolitis $(\mathrm{n}=11)$ \\
\hline Histological diagnosis & $\begin{array}{l}\text { Tubulovillous adenoma }(n=3) \\
\text { Adenocarcinoma }(n=14)\end{array}$ & Active ulcerative colitis $(\mathrm{n}=11)$ \\
\hline
\end{tabular}

5-ASA, 5 aminosalicylic acid; UC, ulcerative colitis.

Inflamed mucosal biopsies from patients with active ulcerative colitis $(\mathrm{n}=11)$ served as disease controls. All endoscopic biopsies were snap frozen in liquid nitrogen and postfixed in fresh $1 \%$ paraformaldehyde pending immunohistochemical evaluation.

\section{Materials and methods}

REVERSE TRANSCRIPTION POLYMERASE CHAIN REACTION (RT-PCR)

Total RNA was purified from $200 \mathrm{mg}$ of frozen tissue according to the method of Chomczynski and Sacchi. ${ }^{20}$ Extracted RNA pellets were washed in $70 \%$ ethanol, dissolved in sterile water, and stored at $-70^{\circ} \mathrm{C}$ until evaluated. Aliquots of each RNA sample $(5 \mu \mathrm{g})$ were reverse transcribed to produce single stranded cDNA using random primers and AMV reverse transcriptase (Invitrogen, Leek, the Netherlands). Samples of cDNA (50 ng) were then analysed by PCR amplification using iNOS specific nucleotide primers and BioTaq DNA polymerase (Bioline, London, UK). Primer sequences were as follows: iNOS sense, 5'-GAG AAA GCC CCC TGT GCC-3' and iNOS antisense, 5'-TAC CGC TTC CAC CCT GGC-3', which amplify a 424 bp cDNA fragment. PCR amplification was carried out for up to 45 cycles as follows: after five minutes denaturation at $93^{\circ} \mathrm{C}$, hot start reactions were initiated (annealing $60^{\circ} \mathrm{C}$ for 30 seconds, extension $72^{\circ} \mathrm{C}$ for 30 seconds, and denaturation $93^{\circ} \mathrm{C}$ for 30 seconds). Semiquantitative PCR data were generated by kinetic analysis and compared with glyceraldehyde-3phosphate dehydrogenase (G3PDH) mRNA values. Products were analysed by $6 \%$ polyacrylamide gel electrophoresis and film autoradiography using radiolabelled DNA size markers (100 bp ladder from Gibco-BRL, Paisley, UK). Products separated in this way were excised, eluted from the gel into $0.5 \mathrm{M}$ ammonium acetate, and ethanol precipitated. The identity of the product was confirmed by direct cycle sequencing using a kit (Circumvent; New England Biolabs, Hitchin, UK).

IMMUNOHISTOCHEMISTRY

iNOS expression and cellular localisation were examined in tissue by immunoperoxidase labelling. Frozen surgical specimens were sectioned and then postfixed in $1 \%$ paraformaldehyde. Non-surgical biopsy specimens were frozen and postfixed in $1 \%$ paraformaldehyde. Endogenous peroxidase activity was blocked in the tissue sections, $(10 \mu \mathrm{m}$ section on APES coated slides), using the endogenous peroxidase suppressor "Immunopure" (Pierce
Laboratories, Chester, UK) for 22 minutes, followed by the application of a $1 / 20$ dilution of normal goat serum to block non-specific staining. The primary antibody, a rabbit polyclonal raised against a peptide corresponding to amino acids 3-22 mapping to the $\mathrm{N}$-terminus of human iNOS, was obtained from Santa Cruz, Santa Cruz, California, USA (N-20). This was applied to sections at a concentration of $0.5-1 \mu \mathrm{g} / \mathrm{ml}$ and incubated for one hour. Subsequently, the second antibody was applied, a goat antirabbit biotinylated antibody (applied at $5 \mu \mathrm{g} / \mathrm{ml}$; Vecta Laboratories, California, USA). This was probed further with $\mathrm{AB}$ vectastain and developed with diaminobenzadene (DAB) for three to five minutes, giving a brown stain at sites of immunolabelling. Normal rabbit serum (concentration up to $2 \mu \mathrm{g} / \mathrm{ml}$ ) was applied on serial sections as a negative control. As an additional control of specificity of labelling, it was ensured that any positive labelling was neutralised by preabsorption of the primary antibody with iNOS peptide. Sections were counterstained with haematoxylin (1/20 dilution).

EXTRACTION AND IMMUNOBLOTTING OF INOS The monospecificity of the primary iNOS antibody (Santa Cruz N-20) used was initially assessed by immunoblots. Purified human recombinant iNOS, eNOS, and nNOS obtained from transfected insect cells were used as standards (donated by R Knowles, GlaxoWellcome, Stevenage, UK). No cross reactivity was seen with the eNOS and nNOS standards, but strong labelling was seen with the purified iNOS (data not shown). This protein was used as a positive standard for tissue blots.

TISSUE EXTRACTION

Colonic mucosa was homogenised in ice cold RIPA buffer containing $25 \mathrm{mM}$ Tris, pH 6.8, $1 \mathrm{mM}$ EDTA, $0.1 \%$ sodium dodecyl sulphate (SDS), 1\% NP40, 1\% sodium deoxycholate, and $0.9 \% \mathrm{NaCl}$. Protease inhibitors were added as follows: $100 \mu \mathrm{g} / \mathrm{ml}$ phenylmethylsulphonylflouride (PMSF), aprotinin containing 5-10 trypsin inhibitor units (TIU)/ml diluted to $30 \mu \mathrm{l} / \mathrm{ml}, 1 \mu \mathrm{g} / \mathrm{ml}$ pepstatin, $0.5 \mu \mathrm{g} /$ $\mathrm{ml}$ leupeptin, and $625 \mu \mathrm{g} / \mathrm{ml}$ n-ethylmaleimide. Samples for SDS polyacrylamide gel electrophoresis (SDS-PAGE) were solubilised in sample buffer containing $62.5 \mathrm{mM}$ Tris/ $\mathrm{HCl}$, $10 \%$ glycerol, $2 \%$ SDS, $0.1 \%$ bromophenol blue, and $100 \mathrm{mM}$ dithiotreitol (DTT), pH 6.8. Equal amounts of protein $(20 \mu \mathrm{g})$ for each homogenate were loaded on to $7.5 \%$ 


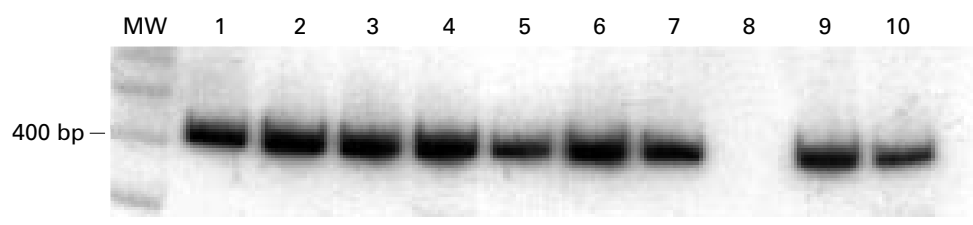

Figure 1 Qualitative RT-PCR analysis of inducible nitric oxide synthase (iNOS) expression in surgical specimens showing the ubiquitous presence of a $424 \mathrm{bp} D N A$ product indicating $i N O S$ expression. MW, molecular weight markers (indicating $400 \mathrm{bp}$ left lane). Lanes 1-6, normal tissue; lanes 7, 9, and 10, diseased specimens; lane 8, negative control.

SDS-PAGE gels and electrophoresed. Separated proteins were transferred to nitrocellulose membrane (Amersham, UK). The membrane was incubated with iNOS primary antibody (as described above) at a similar concentration $(1 \mu \mathrm{g} / \mathrm{ml})$ to that used for immunostaining, followed by probing with a goat antirabbit antibody (diluted 1/5000) linked to horseradish peroxidase (Vecta Laboratories).

Blots were developed by enhanced chemiluminescence (ECL; Amersham, Amersham, $\mathrm{UK})$.

\section{Results}

iNOS mRNA expression was detected in all specimens, both normal and inflamed, using RT-PCR (fig 1). Kinetic PCR analysis revealed increased iNOS production in the inflamed tissues compared with normal tissue when standardised to G3PDH, consistent with previous data $^{7}$ (fig 2). Immunoblotting revealed the presence of a protein of approximately $130 \mathrm{kDa}$ in $77 \%$ of normal and $85 \%$ of diseased specimens, which was shown to comigrate with the iNOS standard. The presence of this band was inhibited by the addition of a $2 \times$ concentration of the immunising N-20 peptide (Santa Cruz) (fig 3). Immunostaining localised iNOS protein to the surface epithelium in $80 \%$ of the histologically normal surgical specimens and in $90 \%$ of the normal endoscopic biopsies. Additional labelling was seen in the crypt epithelium and inflammatory cells of the lamina propria in inflamed mucosa in $85 \%$ of the surgical and in $93 \%$ of the endoscopic biopsy specimens (fig 4), irrespective of any treatment the patients with ulcerative colitis

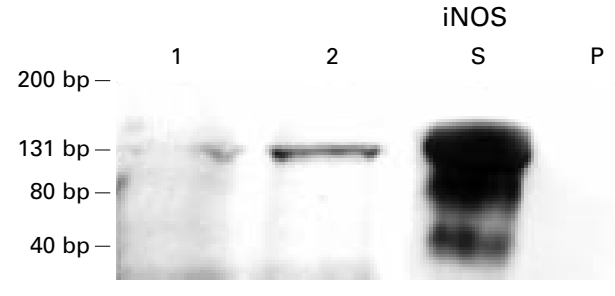

Figure 3 Immunoblotting of surgical mucosal specimens with primary anti-inducible nitric oxide synthase (iNOS) antibody showing band of approximately $130 \mathrm{kDa}$ expressed in normal mucosa, consistent with full length $i N O S$ protein expression. Lanes 1 and 2, normal mucosa; lane $S$, $i N O S$ recombinant protein standard (smaller sized bands indicating $i N O S$ degradation on storage). Lane $P$ shows immunoreactivity of $i$ NOS inhibited by coincubation with the immunising peptide.

received before surgery. For all specimens staining positive, the immunolabelling was neutralised when antibody was preabsorbed with the N-20 iNOS peptide.

\section{Discussion}

Our data demonstrate that iNOS is expressed not only in inflamed mucosa in ulcerative colitis, but also in the epithelium of the noninflamed human colon, as suggested by one previous study, although that report was limited by using immunohistochemistry alone and small numbers of patients. ${ }^{18} \mathrm{~A}$ further report suggested that iNOS enzyme activity was present in the mucosa of a few normal specimens, although they were unable to demonstrate iNOS protein expression itself in these specimens. ${ }^{19}$ This study also suggested that colonic iNOS expression was related to the stage of cancer development, with the highest degree of expression seen in adenomas; that is, precancerous lesions. Our surgical specimens were taken from patients with colorectal cancer or adenomas, although tissue was obtained from a site distant from the lesion. Because local carcinogenic factors might play a role in iNOS induction, we also examined colonic tissue taken endoscopically from patients shown to have completely normal colons, thereby eliminating such effects. All other studies have failed to demonstrate iNOS expression in the normal colon, ${ }^{5-14}$ and have therefore not confirmed the initial report. ${ }^{18}$

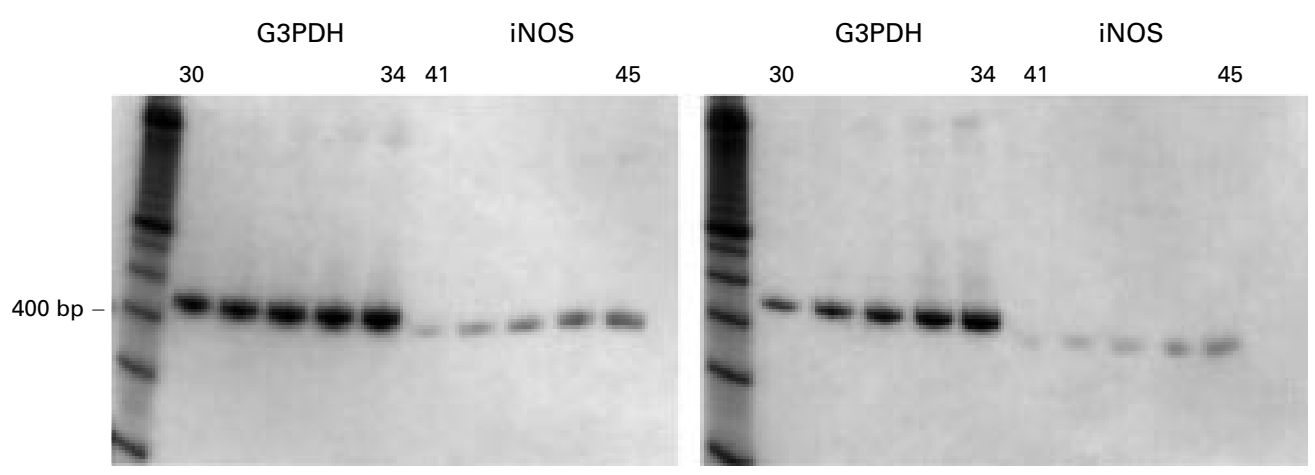

Figure 2 Example of kinetic PCR analysis of inducible nitric oxide synthase (iNOS) expression in a diseased (left hand set) and a normal specimen (right hand set). Densitometrical analysis revealed the expected increase of $i N O S$ product in diseased tissue compared with normal tissue. PCR cycle lengths: G3PDH, 30-34; iNOS, 41-45. G3PDH, glyceraldehyde-3-phosphate dehydrogenase. 

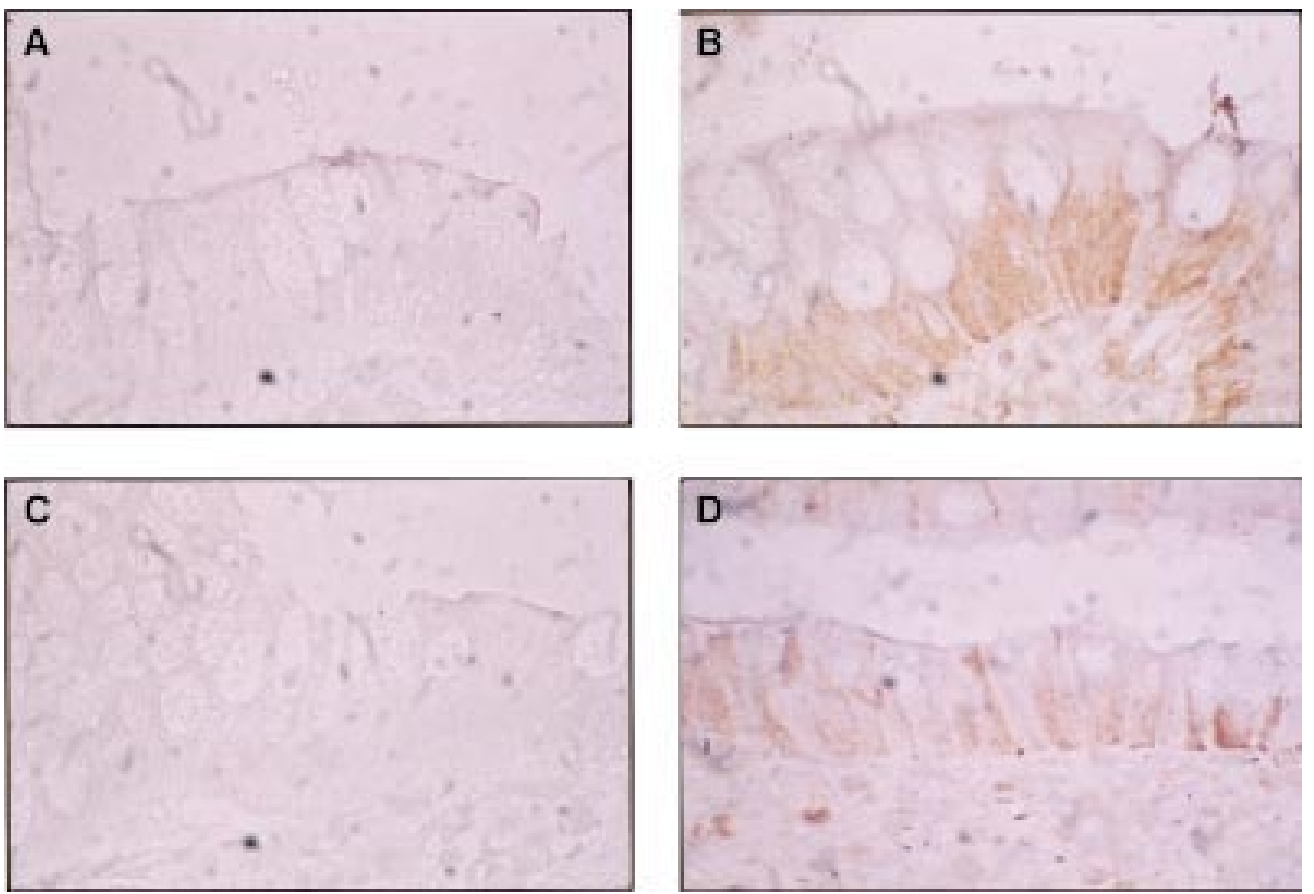

Figure 4 Immunolocalisation of inducible nitric oxide synthase ( $i$ NOS) in surgical specimens showing surface epithelial staining in the normal tissue, and more extensive labelling in the diseased tissue. (A) Non-immune serum, normal mucosa; (B) iNOS expression, normal mucosa; (C) control (primary antibody quenched with $2 \times$ concentration of immunising peptide), normal mucosa; (D) iNOS expression, diseased mucosa. Original magnification $\times 120(A, C$, and $D$, $)$; original magnification $\times 240(B)$.

The expression of iNOS in the normal colonic epithelium is likely to occur in response to luminal factors, such as bacterial lipopolysaccharide (LPS), which are the only locally occurring substances known to induce iNOS. In some ways, this is similar to the expression of iNOS in the epithelium of normal lung, which also occurs in close proximity to such stimulants. All normal specimens expressed iNOS mRNA, with iNOS protein expression in most of these specimens being evaluated. Interestingly, the localisation of iNOS was found to be patchy along the surface epithelium, a feature that we as yet cannot explain. Therefore, it would seem necessary to evaluate large numbers of specimens and to use multiple techniques to obtain representative data in the normal human colon, as illustrated by our study.

Epithelial cell derived NO could provide an oxidative barrier, thereby reducing bacterial translocation through the colonic mucosa and might, therefore, be viewed as part of the local colonic barrier system. However, high concentrations of NO might be cytopathic to epithelial cells at this site, either directly, or as a result of its reaction with superoxide radicals to form peroxynitrite, as occurs in inflammatory conditions of the colon. ${ }^{27}{ }^{21}$ In high concentrations, $\mathrm{NO}$ will also induce apoptosis in some mammalian cells, ${ }^{22}$ whereas evidence is accumulating to suggest that inhibition of apoptosis occurs at lower concentrations of NO. ${ }^{23-26}$ At the cellular level, the chemistry of $\mathrm{NO}$ is ill defined and complex, ${ }^{26}{ }^{27}$ with the potential of NO either to induce or inhibit apoptosis in the normal colonic epithelium, depending upon the luminal and cellular microenvironment.
Other pathophysiological effects of NO and its oxides include nitrosation of amines, ${ }^{21}$ 28-30 which in the colonic epithelium would lead to increased concentrations of luminal nitrosamines with their carcinogenic potential. In addition, NO has been shown to deaminate DNA bases, thereby having the potential to alter the genome directly. ${ }^{3132}$

Dietary factors are implicated in colorectal carcinoma, ${ }^{33}{ }^{34}$ including red meat, which increases faecal concentrations of $N$-nitroso compounds. ${ }^{35}$ The mechanism by which this increase in nitrosamine concentration occurs is uncertain, but may be via epithelial iNOS expression, with resultant nitrosation of luminal amines by $\mathrm{NO}$, thus creating a luminal microenvironment that is more likely to lead to carcinogenesis. $^{35}$

In summary, using multiple techniques we have shown the expression of iNOS in the mucosa of normal human colon in a large number of specimens. The resultant NO produced by this enzyme might have beneficial effects by both maintaining epithelial barrier function, with prevention of bacterial translocation, and by stimulating apoptosis. Conversely, in certain luminal environments, epithelial NO might be carcinogenic to colonic epithelial cells. Therefore, mucosal iNOS expression might be a link between diet or some other luminal component and colorectal carcinogenesis. Further studies are required to identify possible stimulants of iNOS induction in the normal colon, whether dietary or another luminal factor, and to evaluate the effects of this iNOS expression in the normal colonic epithelium with regard to apoptosis and carcinogenesis. 
1 Moncada S, Palmer RMJ, Higgs EA. Nitric oxide: physiology, pathophysiology, Higgs EA. Nitric oxide: physiology, pathophysio

2 Nathan C, Xie Q-W. Nitric oxide synthesis: roles, tolls and controls. Cell 1994;78:915-18.

3 Marletta $M$. Nitric oxide synthase structure and mechanism. F Biol Chem 1993;268:12231-4.

4 Forstermann U, Kleinhert H. Nitric oxide synthase; expression and expressional control of the three isoforms. Naunyn Schmiedebergs Arch Pharmacol 1995;352:351-64.

5 Middleton SJ, Shorthouse M, Hunter JO. Increased nitric oxide synthesis in ulcerative colitis. Lancet 1993;341:465-6.

6 Boughton-Smith NK, Evans SM, Hawkey CJ, et al. Nitric oxide synthase activity in ulcerative colitis and Crohn's disease. Lancet 1993;342:336-40.

7 Singer II, Kawka DW, Scott S, et al. Expression of inducible nitric oxide synthase and nitrotyrosine in colonic epithelium in inflammatory bowel disease. Gastroenterology 1996; 111:871-85.

8 Godkin AJ, De Belder AJ, Villa L, et al. Expression of nitric oxide synthase in ulcerative colitis. Eur $\mathcal{f}$ Clin Invest oxide synthase in

9 Ikeda I, Kasajima T, Ishiyama S, et al. Distribution of inducible nitric oxide synthase in ulcerative colitis. Am $\mathcal{F}$ Gastroenterol 1997;92:1339-41.

10 Kimura H, Miura S, Shigematsu T, et al. Increased nitric oxide production and inducible nitric oxide synthase activity in colonic mucosa of patients with active ulcerative colitis and Crohn's disease. Dig Dis Sci 1997;42:1047-54.

11 Kolios G, Rooney N, Murphy CT, et al. Expression of inducible nitric oxide synthase activity in human colon epithelial cells: modulation by $\mathrm{T}$ lymphocyte derived cytokines. Gut 1998;43:56-63.

12 Leonard N, Bishop AE, Polak JM, et al. Expression of nitric oxide synthase in inflammatory bowel disease is no affected by corticosteroid treatment. F Clin Pathol 1998;51: 750-3.

13 Rachmilewitz D, Stamler JS, Bachwich D, et al. Enhanced colonic nitric oxide generation and nitric oxide synthase colonic nitric oxide generation and nitric oxide synthase
activity in ulcerative colitis and Crohn's disease. Gut 1995; activity in ulc

14 Kimura H, Hokari R, Miura S, et al. Increased expression of an inducible isoform of nitric oxide synthase and the formation of peroxynitrite in colonic mucosa of patients with active ulcerative colitis. Gut 1998;42:180-6.

15 Guo FH, DeRaeve HR, Rice TW, et al. Continuous nitric oxide synthesis by inducible nitric oxide synthase in normal human airway epithelium in vivo. Proc Natl Acad Sci US A 1995;92:7809-13.

16 Hoffman R, Zhang G, Nussler NC, et al. Constitutive expression of inducible nitric oxide synthase in the mouse ileal mucosa. Am f Physiol 1997;272:G383-92

17 Tepperman BL, Brown JF, Korolkiewicz R, et al. Nitric oxide synthase activity, viability and cyclic GMP levels in rat colonic epithelial cells: effect of endotoxin challenge. $\mathcal{F}$ Pharmacol Exp Ther 1994;271:1477-82.

18 Moochhala S, Chatwal VJS, Chan STF, et al. Nitric oxide synthase activity and expression in human colorectal cancer. Carcinogenesis 1996;17:1171-4.
19 Ambs S, Merriam WG, Bennett WP, et al. Frequent nitric oxide synthase- 2 expression in human colon adenomas:
implication for tumour angiogenesis and colon cancer proimplication for tumour angiogenesis a

20 Chomczynski P, Sacchi N. Single step method of RNA isolation by acid guanidinium thiocyanate-phenol-chloroform extraction. Anal Biochem 1987;162:156-9.

21 Miller MJS, Grisham MB. Nitric oxide as a mediator of inflammation? You had better believe it. Mediators Inflamm 1995;4:387-96.

22 Nicoreta P, Bonfoco E, Brune B, et al. Mechanism for nitric oxide induced cell death: involvement of apoptosis. $A d v$ Neuroimmunol 1997;5:411-20.

23 Dimmeler S, Haendler J, Nehls M, et al. Suppression of apoptosis by nitric oxide via inhibition of interleukin apoptosis by nitric oxide via inhibition of interleukin protein (CPP)-32-like proteases. F Exp Med 1997;185:601proteir 7 .

24 Tzeng E, Kim YM, Pitt BR, et al. Adenoviral transfer of the inducible nitric oxide synthase gene blocks endothelial apoptosis. Surgery 1997;122:255-63.

25 Kim YM, deVera ME, Watkins SC, et al. Nitric oxide protects rat hepatocytes from tumour necrosis factoralpha-induced apoptosis by inducing heat shock protein 70 expression. F Biol Chem 1997;272:1402-11.

26 Mannick JB, Asano K, Izumi K, et al. Nitric oxide produced by human B lymphocytes inhibits apoptosis and EpsteinBarr virus reactivation. Cell 1994;79:1137-46.

27 Crow JP, Beckman JS. Reactions between nitric oxide, superoxide, and peroxynitrite: footprints of peroxynitrite in vivo. Adv Pharmacol 1995;34:17-43.

28 Wink DL, Hanbauer I, Grisham MB, et al. Chemical biology of nitric oxide: regulation and protective and toxic mechanisms. Curr Top Cell Regul 1996;34:159-87.

29 Marletta MA. Mammalian synthesis of nitrite, nitrate, nitric oxide, and N-nitrosating agents. Chem Res Toxicol 1988;1: 249-57.

$30 \mathrm{Wu} \mathrm{Y,} \mathrm{Brouet} \mathrm{I,} \mathrm{Calmels} \mathrm{S,} \mathrm{et} \mathrm{al.} \mathrm{Increased} \mathrm{endogenous}$ $\mathrm{N}$-nitrosamine and nitrate formation by induction of nitric oxide synthase in rats with acute hepatic injury caused by Propionibacterium acnes and lipopolysaccharide administration. Carcinogenesis 1993;14:7-10.

31 Wink DA, Kasprzak KS, Maragos CM, et al. DNA deaminating ability and genotoxicity of nitric oxide and its progenitors. Science 1991;254:1001-3.

32 Nguyen T, Brunson D, Crespi CL, et al. DNA damage and mutation in human cells exposed to nitric oxide in vitro. Proc Natl Acad Sci U S A 1992;89:3033-4.

33 Armstrong B, Doll R. Environmental factors and cancer incidence in different countries. Int $\mathcal{F}$ Cancer 1975;15:61731.

34 Giovannucci E, Rimm E, Stampfer MJ, et al. Intake of fat, meat, and fibre in relation to risk of colon cancer in men. Cancer Res 1994;54: 2390-2397.

35 Bingham SA, Pignatelli B, Pollock JRA, et al. Does increased endogenous formation of N-nitroso compounds in the human colon explain the association between red meat and colon cancer? Carcinogenesis 1996;17:515-23.

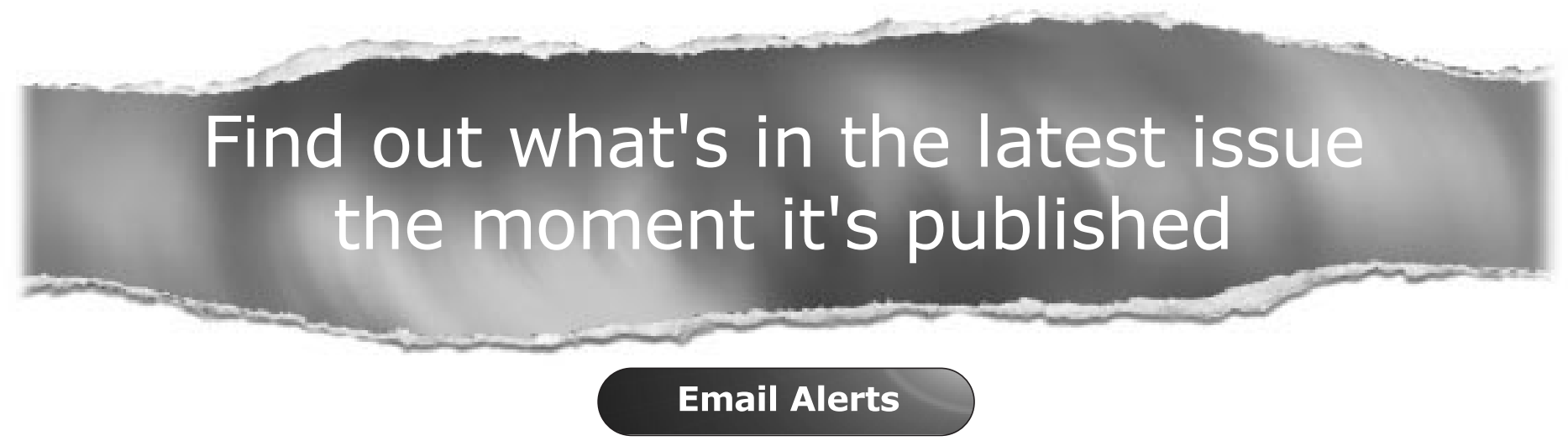

Sign up to receive the table of contents by email every month. You can select from three alerts: Table of Contents (full), TOC Awareness (notice only); Journal of Clinical Pathology related announcements.

www.jclinpath.com 